\title{
DETERMINAÇÃO DA DIFUSIVIDADE EFETIVA DE RAIZ DE CHICÓRIA ${ }^{1}$
}

\section{RAFAEL A. DE OLIVEIRA ${ }^{2}$, WILLIAN P. DE OLIVEIRA ${ }^{3}$, KIL J. PARK ${ }^{4}$}

RESUMO: A inulina é um frutooligossacarídeo encontrado em diversos produtos agrícolas, dentre os quais o alho, a banana, a alcachofra de Jerusalém e a raiz de chicória. A inulina é geralmente utilizada em países desenvolvidos, como substituto do açúcar e/ou gordura devido as suas características que a enquadram como alimento funcional e dietético. A raiz de chicória é utilizada como fonte e matériaprima para a extração comercial de inulina. Os experimentos constituíram-se na secagem das raízes fatiadas em um secador convectivo com fluxo do ar perpendicular, com base em um planejamento fatorial. Pôde-se determinar a difusividade efetiva (variável dependente) para cada uma das combinações das variáveis independentes (temperatura e velocidade do ar), sendo as curvas desses resultados ajustadas pela solução da Segunda Lei de Fick e pelo modelo de Page. A difusividade efetiva variou de $3,51 \times 10^{-10} \mathrm{~m}^{2} \mathrm{~s}^{-1}$ até $10,36 \times 10^{-10} \mathrm{~m}^{2} \mathrm{~s}^{-1}$. Concluiu-se que, para a região de valores estudada, somente a temperatura do ar é estatisticamente significativa. Obteve-se, assim, modelo matemático de primeira ordem, representando o comportamento da difusividade efetiva em função da temperatura do ar. A melhor condição de secagem obtida foi a que utiliza a maior temperatura de ar de secagem.

PALAVRAS-CHAVE: inulina, secagem, modelo de Page.

\section{DETERMINATION OF EFFECTIVE DIFFUSIVITY OF CHICORY ROOT}

ABSTRACT: Inulin is a fructooligosacharide found in diverse agricultural products, amongst them garlic, banana, Jerusalem artichoke and chicory root. Inulin generally is used in developed countries, as a substitute of sugar and/or fat due to its characteristics of fitting as functional and dietary food. Chicory root is usually used as source and raw material for commercial extration of inulin. The experiments consisted on drying sliced chicory roots based on a factorial experimental design in a convective dryer whose alows the air to pass perpendicularly through the tray. Effective diffusivity (dependent variable) has been determined for each experimental combination of independent variables (air temperature and velocity). The data curves have been fitted by the solution of the second Fick law and Page's model. Effective difusivity varied from $3.51 \times 10^{-10} \mathrm{~m}^{2} \mathrm{~s}^{-1}$ to $1.036 \times 10^{-10} \mathrm{~m}^{2} \mathrm{~s}^{-1}$. It is concluded that, for the range of studied values, air temperature is the only statistically significant variable. So, a first order mathematical model was obtained, representing effective diffusivity behavior as function of air temperature. The best drying condition was correspondent to the trial using the highest drying air temperature.

KEYWORDS: inulin, drying, Page's model.

\footnotetext{
${ }^{1}$ Escrito para apresentação no XXXIII Congresso Brasileiro de Engenharia Agrícola - CONBEA 2004.

${ }^{2}$ Engo Agrícola, Doutorando em Tecnologia Pós-Colheita, Faculdade de Engenharia Agrícola, UNICAMP, Campinas - SP, Fone/Fax: (0XX19) 3788.1076, augustus@agr.unicamp.br.

${ }^{3}$ Graduando em Engenharia Agrícola, Faculdade de Engenharia Agrícola, UNICAMP, wpo@agr.unicamp.br.

${ }^{4}$ Professor Titular, Faculdade de Engenharia Agrícola, UNICAMP, kil@ agr.unicamp.br.

Recebido pelo Conselho Editorial em: 2-8-2004

Aprovado pelo Conselho Editorial em: 13-12-2005
} 


\section{INTRODUÇÃO}

Chicória (Cichorium intybus L.) é uma planta de raiz tuberosa cujo carboidrato de reserva é a inulina, presente em suas raízes com teor de frutose muito elevado (cerca de 94\%). Recentemente, a inulina foi identificada como ingrediente capaz de substituir a gordura ou o açúcar, com baixa contribuição calórica. Por atuar junto ao organismo de maneira similar às fibras dietéticas, a inulina, presente nas raízes de chicória, pode, ainda, ser utilizada na produção de alimentos funcionais.

No Brasil, ainda não é significativa a exploração comercial da chicória para a extração de inulina, sendo escassos os estudos científicos sobre seu processamento pós-colheita. Em geral, esses estudos ainda são restritos à área agronômica, na seleção de cultivares mais adequada ao nosso clima. Trabalhos sobre a secagem da raiz de chicória são raros, principalmente no que se refere à produção de inulina.

A raiz de chicória é um produto altamente perecível, exigindo, do ponto de vista industrial, um curto período de processamento, ou seja, equipamentos superdimensionados e com grande tempo ocioso durante a entressafra. Assim, para permitir o melhor dimensionamento de uma planta de processamento para obtenção de inulina e garantir o fornecimento contínuo do produto, é necessário criar alternativas para disponibilizar a raiz de chicória ao longo do ano. A secagem seria, então, uma alternativa para diminuir a atividade de água da matéria-prima e, conseqüentemente, prolongar a sua vida útil.

Durante a secagem, é necessário o fornecimento de calor para evaporar a água do material e também deve haver um sorvedor para remover o vapor d'água da superfície do material a ser seco (BROD et al., 1999).

Os produtos biológicos são muito diferentes entre si, devido a variações em sua forma, estrutura e suas dimensões, além de as condições de secagem serem muito diversas de acordo com as propriedades do ar de secagem e com a forma com que se faz o contato ar-produto. Quando o produto é colocado em contato com o ar de secagem, ocorre transferência do calor do ar ao produto sob o efeito da diferença de temperatura existente entre eles. Simultaneamente, a diferença de pressão parcial de vapor de água existente entre o ar e a superfície do produto determina a transferência de vapor para o ar. Uma parte do calor que chega ao produto é utilizada para evaporar a água e a outra para elevar a sua temperatura (DAUDIN, 1983).

A evolução dessas transferências simultâneas de calor e de massa no decorrer da operação de secagem faz com que essa seja dividida esquematicamente em três períodos: período de indução, período em taxa constante e período em taxa decrescente de secagem.

BRACKEL (1980) resumiu e classificou em 12 categorias grande número de curvas de cinética de secagem experimentais publicadas na literatura.

$\mathrm{Na}$ secagem da maioria dos produtos biológicos, somente o período de secagem em taxa decrescente (período 2) está presente. SHERWOOD (1929 a, b), descrevendo a secagem do pescado, observou que o período 1 é muito mais curto que aquele indicado para a categoria. SARAVACOS \& CHARM (1962) e FORNELL et al. (1980) indicavam também curtos períodos 1 para os produtos alimentares, mas a temperatura do produto evolui de sua temperatura inicial até a temperatura do ar, sem estabilizar na temperatura de bulbo úmido.

O período de secagem em taxa decrescente é, às vezes, dividido em dois ou três outros períodos. Entretanto, para os produtos agrícolas e alimentares, é bem difícil indicar com clareza as divisões nas curvas experimentais de secagem.

No decorrer do período de secagem, a taxa decrescente corresponde à migração interna da água que fixa a cinética de secagem. Os diferentes mecanismos que descrevem o movimento da água são: o 
movimento de água líquida sob efeito das forças de gravidade (desprezível na secagem de produtos biológicos); a migração capilar da água líquida sob a ação da tensão superficial; a difusão de água líquida sob o efeito de gradiente de umidade segundo a Lei de Fick; a difusão de água líquida adsorvida sobre as superfícies internas dos poros vazios (somente para teores de água muito baixos); a difusão de vapor sob o efeito de gradiente de pressão parcial de vapor de água; o escoamento de água sob o efeito de uma diferença de pressão total entre o interior e o exterior de produtos alimentícios, e a migração de água líquida ou vapor sob o efeito de gradiente de temperatura.

O período de taxa decrescente de secagem é quase sempre o único observado para a secagem de produtos agrícolas e alimentícios. A complexidade dos fenômenos de secagem conduz os pesquisadores a proporem numerosas teorias e múltiplas fórmulas empíricas para predizerem a taxa de secagem.

A teoria difusional apóia-se exclusivamente sobre a lei de Fick, que expressa que o fluxo de massa por unidade de área é proporcional ao gradiente de concentração de água. Utilizando a lei de Fick na equação de balanço de massa de água no interior do produto, obtém-se:

$$
\frac{\partial \mathrm{X}}{\partial \mathrm{t}}=\nabla\left(\mathrm{D}_{\mathrm{ef}} \nabla \mathrm{X}\right)
$$

em que,

$D_{\text {ef }}$ - difusividade efetiva, $\mathrm{m}^{2} \mathrm{~s}^{-1}$

$\mathrm{X}$ - teor de água, $\mathrm{kg}_{\mathrm{H} 2 \mathrm{O}} / \mathrm{kg}_{\mathrm{ms}}, \mathrm{e}$

$\mathrm{t}$ - tempo, s.

Independentemente dos trabalhos sobre secagem, CRANK (1975) calculou grande número de soluções da equação de difusão para condições iniciais e de contorno variadas. Entretanto, essas soluções se aplicam aos sólidos de formas geométricas simples (corpos semi-infinitos, placas, cilindros e esferas) e quando a difusividade é constante ou varia linearmente ou exponencialmente com a concentração de água. Para o caso de secagem em sistemas de coordenadas cartesianas, com direção unidirecional em uma placa de espessura 2L:

$$
\frac{\partial \mathrm{X}}{\partial t}=\frac{\partial}{\partial \mathrm{z}}\left(\mathrm{D}_{\mathrm{ef}} \frac{\partial \mathrm{X}}{\partial \mathrm{z}}\right)
$$

Assume-se, na solução da eq.(2), as seguintes condições iniciais e de contorno e a definição (3):

Teor de água inicial uniforme:

Teor de água máxima no centro:

Teor de água constante na superfície:

$\bar{X}=\frac{1}{L} \int_{0}^{L} X(z, t) d z$

Aplicando-se a eq.(3) tem-se a solução:

$$
Y=\frac{\bar{X}-X_{e q}}{X_{o}-X_{e q}}=\frac{8}{\pi^{2}} \sum_{i=0}^{\infty} \frac{1}{(2 i+1)^{2}} \exp \left[-(2 i+1)^{2} \pi^{2} D_{\text {ef }} \frac{t}{4 L^{2}}\right]
$$


em que,

$\mathrm{D}_{\mathrm{ef}}$ - difusividade efetiva, $\mathrm{m}^{2} \mathrm{~s}^{-1}$;

$\mathrm{Y}$ - adimensional de teor de água, adimensional;

$\overline{\mathrm{X}}$ - teor de água médio, $\mathrm{kg}_{\mathrm{H} 2 \mathrm{O}} / \mathrm{kg}_{\mathrm{ms}}$;

$\mathrm{X}_{\mathrm{eq}}$ - teor de água de equilíbrio, $\mathrm{kg}_{\mathrm{H} 2 \mathrm{O}} / \mathrm{kg}_{\mathrm{ms}}$;

$\mathrm{X}_{0}$ - teor de água no instante inicial, $\mathrm{kg}_{\mathrm{H} 2 \mathrm{O}} / \mathrm{kg}_{\mathrm{ms}}$;

i - número de termos na série;

$\mathrm{t}$ - tempo, s;

L - comprimento característico, semi-espessura da amostra, m, e

$\mathrm{z}$ - direção da transferência, $\mathrm{m}$.

O coeficiente de difusão $\left(D_{\text {ef }}\right)$ é uma difusividade efetiva que engloba os efeitos de todos os fenômenos que podem intervir sobre a migração da água, e seu valor é sempre obtido pelo ajuste de valores experimentais. A solução da equação de difusão utilizada é uma das mais simples e parece ser a principal razão de seu emprego. Pode-se entender a difusividade como a facilidade com que a água é removida do material. Como a difusividade varia conforme mudam as condições de secagem (temperatura e velocidade do ar), ela não é intrínseca ao material. Assim, convenciona-se chamá-la de difusividade efetiva.

Em algumas situações, a teoria difusional não é adequada para ajustar o comportamento da taxa de secagem devido a interferências no efeito de resistência interna do material. Para essas situações, podem-se aplicar alguns modelos empíricos, como o modelo de Page (PAGE, 1949), mostrado na eq.(5).

$$
Y=\frac{\bar{X}-X_{e q}}{X_{o}-X_{e q}}=\exp \left(-G t^{j}\right)
$$

em que,

G, j - coeficientes do modelo de Page.

\section{MATERIAL E MÉTODOS}

\section{Matéria-prima}

Foi escolhida a melhor variedade de chicória, segundo resultados fornecidos pelo CPQBA/UNICAMP, ou seja, aquela que apresentou os melhores resultados agronômicos (produtividade, resistência às pragas, facilidade no manejo, etc.) e melhor produção de inulina. $\mathrm{O}$ plantio foi realizado no outono de 2003 (20 de março a 21 de junho), nas dependências da UNICAMP, no campo experimental da Faculdade de Engenharia Agrícola. A colheita foi feita conforme a realização dos experimentos, ou seja, de acordo com a capacidade do sistema de secagem, de forma a evitar perda de material. Essa teve início no final da primavera, respeitando a antecipação à floração. As raízes utilizadas nos experimentos foram fatiadas em multiprocessador, sendo selecionadas as fatias de espessura mais homogênea possível. Essas fatias foram distribuídas por toda a superfície da bandeja utilizada na secagem.

\section{Planejamento experimental}

Os níveis das variáveis utilizadas nos ensaios foram determinados a partir de um planejamento experimental, sendo esse baseado na metodologia de superfície de resposta, com dois níveis para cada variável independente (temperatura e velocidade do ar de secagem), totalizando $2^{2}=4$ experimentos. Esses pontos fatoriais são apenas para avaliar os efeitos das variáveis e suas interações, não sendo possível, nesse estágio, otimizar o processo. Para o planejamento utilizado, deve-se ainda avaliar o 
erro puro, incluindo no mínimo três repetições dos pontos centrais. Optou-se por utilizar mais quatro ensaios, chamados de ensaios de extrapolação da faixa de análise como complemento para a visualização das influências. Nesse caso, o número total de ensaios foi de: $4+3+4=11$, como mostra a seguinte matriz experimental (Tabela 1).

TABELA 1. Níveis das variáveis codificada e real para o planejamento experimental da secagem.

\begin{tabular}{cccccc}
\hline \multirow{2}{*}{ Ensaio } & \multicolumn{2}{c}{ Variável Codificada } & \multicolumn{2}{c}{ Variável Real } \\
\cline { 2 - 6 } & & $\mathrm{X}_{1}$ & $\mathrm{X}_{2}$ & $\mathrm{~T}_{\mathrm{sec}}\left({ }^{\circ} \mathrm{C}\right)$ & $\mathrm{v}\left(\mathrm{m} \mathrm{s}^{-1}\right)$ \\
\hline \multirow{2}{*}{ Pontos } & 1 & -1 & -1 & 60,0 & 0,50 \\
fatoriais & 2 & +1 & -1 & 80,0 & 0,50 \\
& 3 & -1 & +1 & 60,0 & 1,00 \\
& 4 & +1 & +1 & 80,0 & 1,00 \\
\hline \multirow{2}{*}{ Pontos } & 5 & 0 & 0 & 70,0 & 0,75 \\
centrais & 6 & 0 & 0 & 70,0 & 0,75 \\
& 7 & 0 & 0 & 70,0 & 0,75 \\
\hline \multirow{2}{*}{ Pontos de } & 8 & $-1,41$ & 0 & 42,5 & 0,75 \\
Extrapolação & 10 & $+1,41$ & 0 & 112,8 & 0,75 \\
& 11 & 0 & $-1,41$ & 70,0 & 0,35 \\
& & 0 & $+1,41$ & 70,0 & 1,41 \\
\hline
\end{tabular}

Essa metodologia segue modelo contendo termos de primeira ordem e da interação entre os termos, conforme eq.(6).

$$
\mathrm{D}_{\text {ef }}=\mathrm{b}_{0}+\mathrm{b}_{1} \mathrm{~T}+\mathrm{b}_{2} \mathrm{v}+\mathrm{b}_{12} \mathrm{Tv}
$$

\section{Secagem}

A secagem foi realizada no mesmo secador convectivo utilizado por BROD et al. (2003). Diferentemente do trabalho citado, foi utilizada apenas uma bandeja na câmara do secador, ocupando, assim, apenas a metade esquerda dela. A outra metade foi vedada, assim como as laterais da câmara, para restringir o fluxo de ar apenas para a bandeja e somente na direção vertical.

Depois de realizado o processo de secagem, as curvas de secagem foram construídas com o adimensional de teor de água (Y) da raiz de chicória no decorrer do tempo de secagem e indicam a marcha de decaimento do teor de água do material. Os valores do adimensional de teor de água foram calculados com o teor de água no equilíbrio por meio da determinação da atividade de água das raízes de chicória. As difusividades efetivas (Segunda Lei de Fick) foram ajustadas utilizando a regressão não-linear do pacote estatístico STATISTICA (1995), assim como os coeficientes do modelo de Page.

Terminada a secagem, a amostra de raiz de chicória seca foi utilizada para determinar a massa seca, segundo metodologia da ASSOCIATION OF OFFICIAL ANALYTICAL CHEMISTS (1995).

\section{RESULTADOS E DISCUSSÃO}

Com os dados obtidos nos testes de secagem para cada ponto do modelo fatorial completo, pôdese obter a curva de secagem para cada grupo de experimentos (fatorial, central e de extrapolação). Essas curvas, em que as numerações dos ensaios da figura correspondem às numerações dos experimentos da Tabela 1, são mostradas nas Figuras 1, 2 e 3, respectivamente.

Observou-se na Figura 1 que, devido à variação das variáveis estar apenas entre 60 e $80{ }^{\circ} \mathrm{C}$ e 0,50 e $1,00 \mathrm{~m} \mathrm{~s}^{-1}$, as curvas apresentaram também pequena variação entre si. 


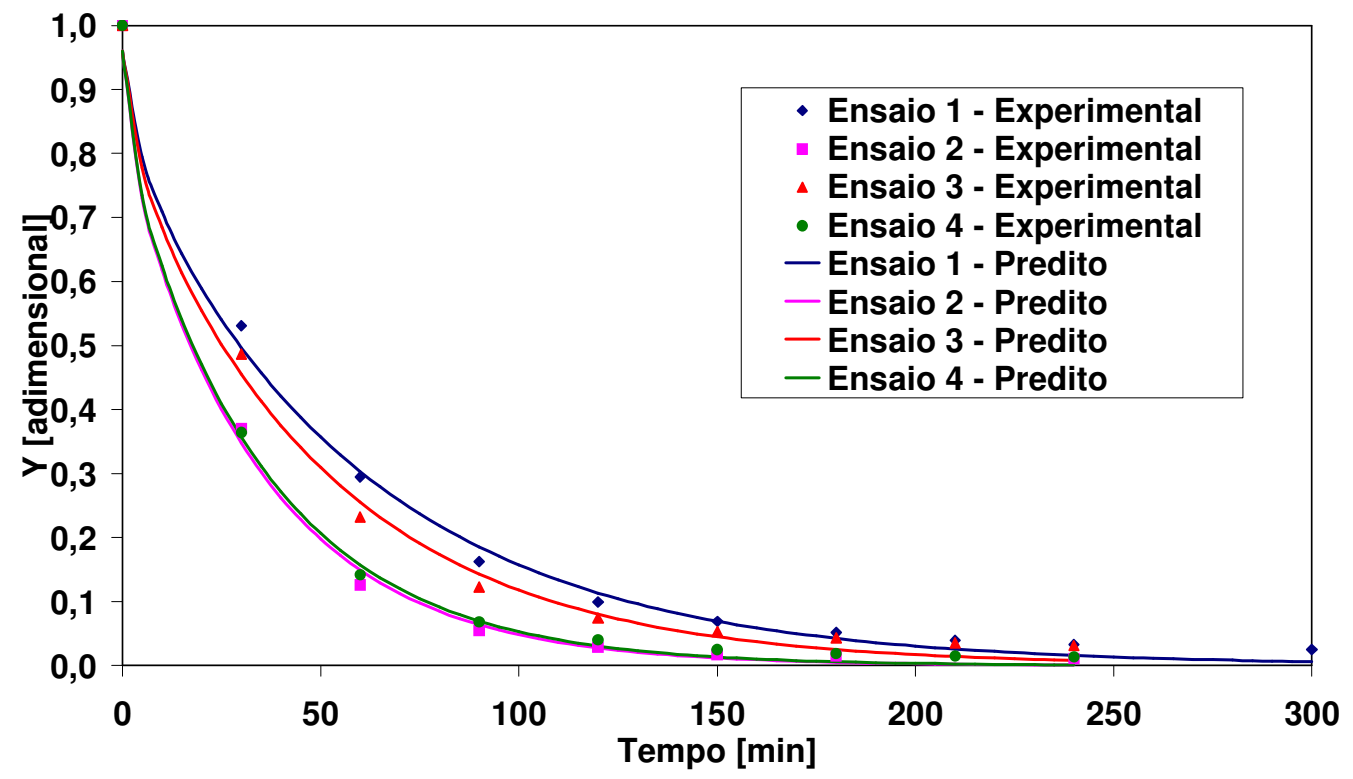

FIGURA 1. Curvas de secagem de raízes de chicória (experimental e estimada) para os ensaios fatoriais, obtidas pelo modelo de Fick.

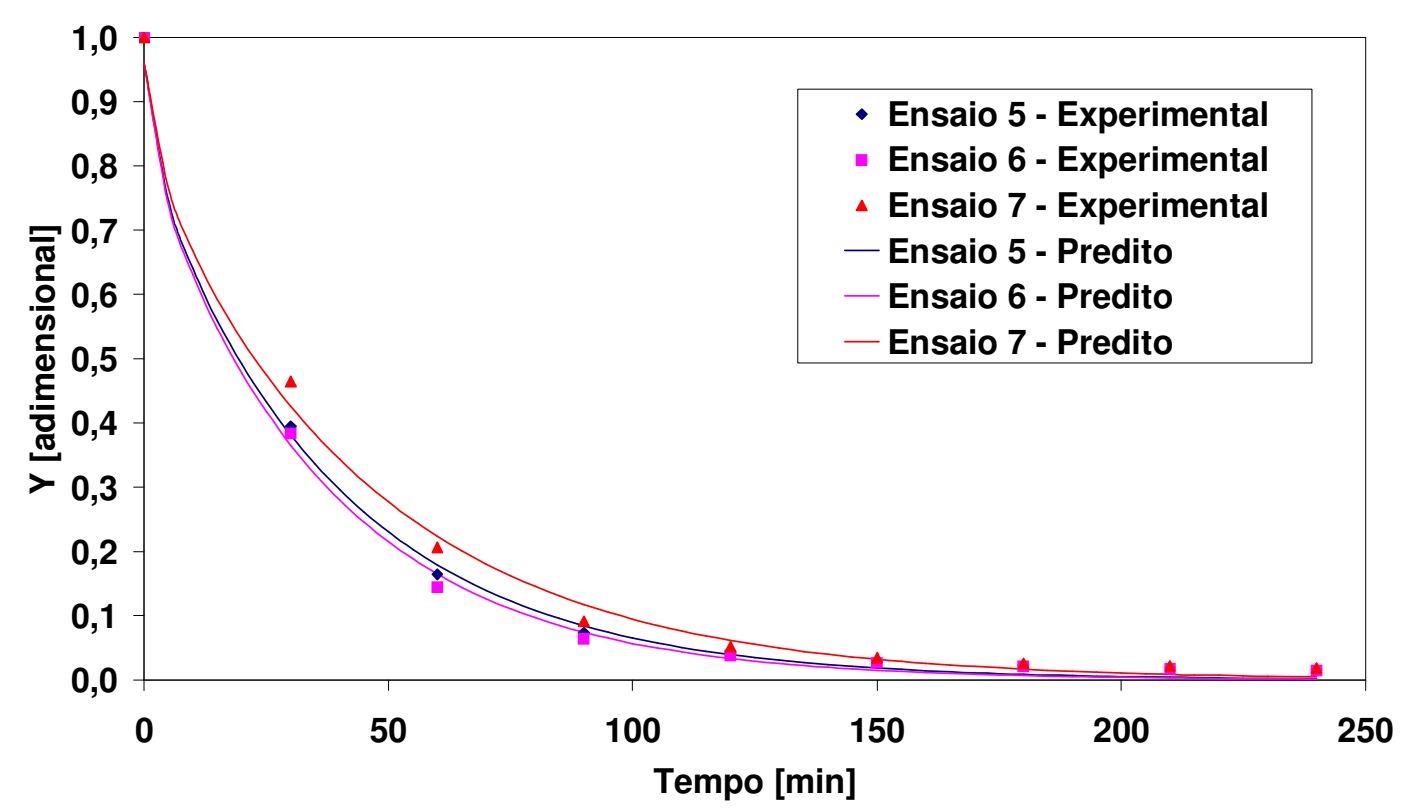

FIGURA 2. Curvas de secagem de raízes de chicória (experimental e estimada) para os ensaios centrais, obtidas pelo modelo de Fick.

Como as condições de secagem dos pontos centrais (Figura 2) são as mesmas, ou seja, já que não existe variação nos valores das variáveis codificadas entre cada ponto, as curvas apresentaram-se muito próximas umas das outras, como era esperado. 


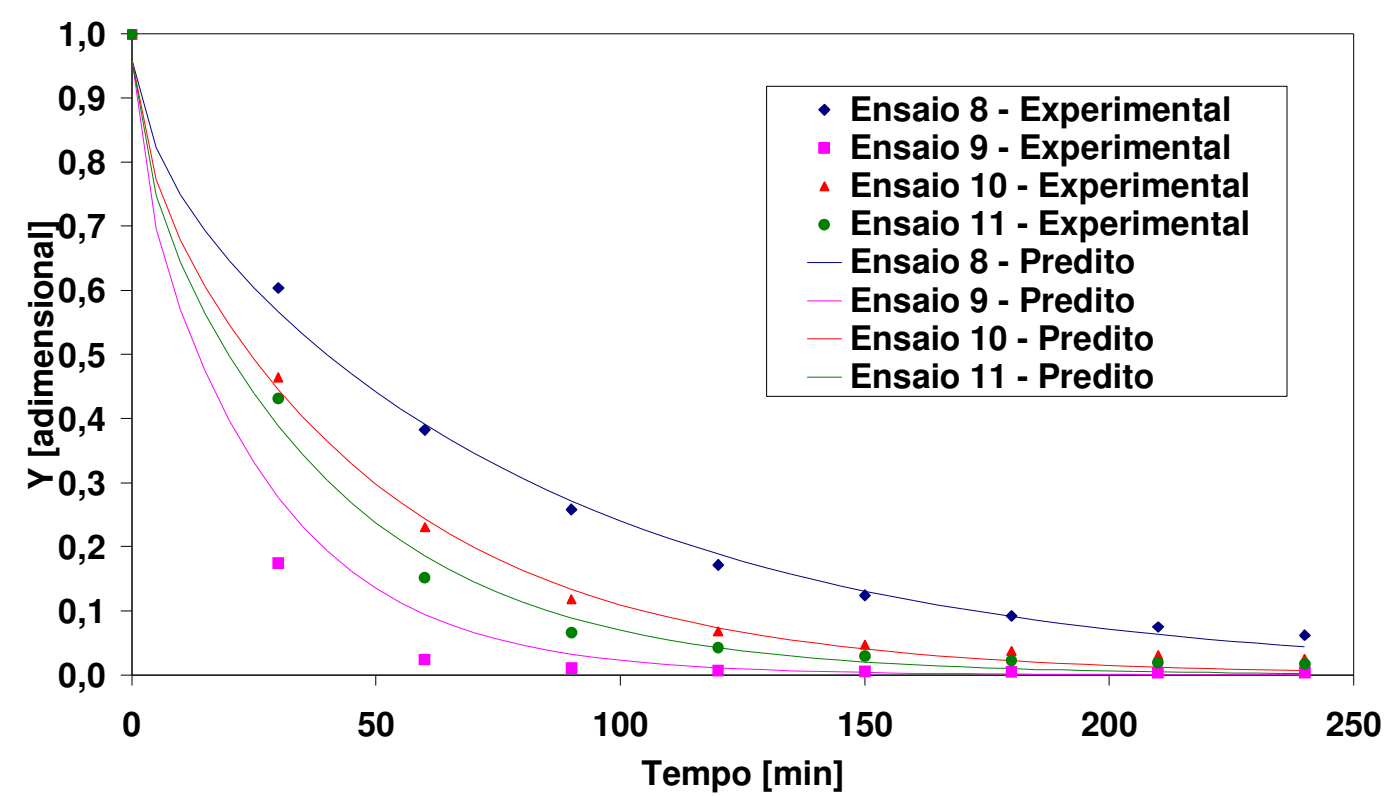

FIGURA 3. Curvas de secagem de raízes de chicória (experimental e estimada) para os ensaios de extrapolação, obtidas pelo modelo de Fick.

Devido à maior diferença dos níveis das variáveis entre os ensaios (Figura 3), observou-se maior discrepância entre as curvas de secagem. Além disso, pôde-se notar que os ensaios que tinham variação nos valores da temperatura ( 8 e 9), apresentaram diferença mais acentuada entre si do que os pontos 10 e 11, que apresentaram variação na velocidade do ar. Na Figura 4, são mostrados os resíduos encontrados no ajuste das curvas dos ensaios de extrapolação pelo modelo de Fick.

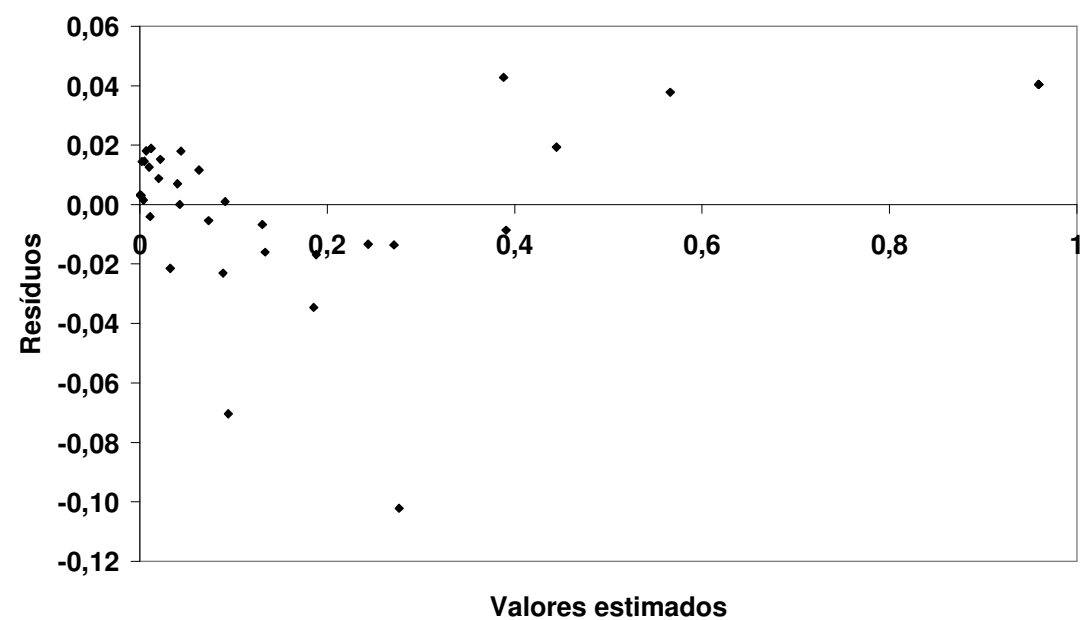

FIGURA 4. Resíduos encontrados nos ajustes das curvas de secagem de raiz de chicória relativas aos ensaios de extrapolação obtidos pelo modelo de Fick.

Na Figura 5, mostram-se as curvas de secagem referentes aos ensaios de extrapolação e respectivos resíduos, obtidos pelos ajustes por meio do modelo de Page.

A partir da eq.(4), utilizando o programa computacional STATISTICA versão 5.0, obtiveram-se os seguintes valores de difusividade efetiva e dos coeficientes da equação de Page [eq.(5)] mostrados na Tabela 2. 

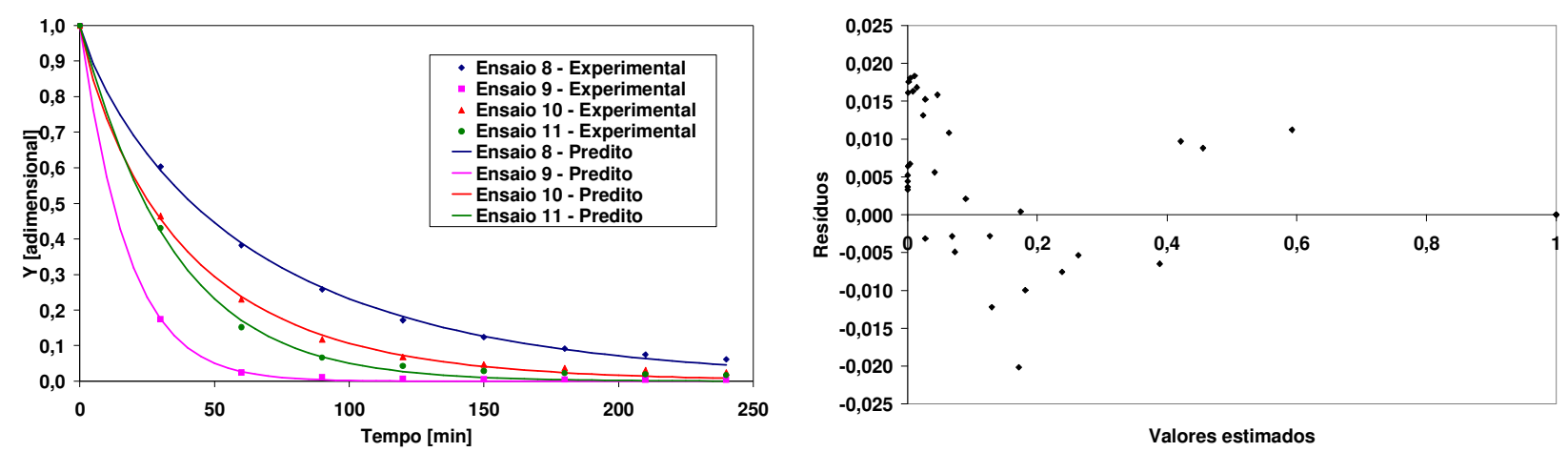

FIGURA 5. Curvas de secagem de raízes de chicória (experimental e estimada) para os ensaios de extrapolação, obtidas pelo modelo de Page e respectivo resíduos.

TABELA 2. Difusividade efetiva, coeficiente de determinação e coeficientes da equação de Page.

\begin{tabular}{|c|c|c|c|c|c|c|}
\hline \multirow{2}{*}{ Ensaios } & \multicolumn{2}{|c|}{ Variáveis } & \multirow{2}{*}{$D_{\text {ef }}\left(x 10^{-10}\right)\left[\mathrm{m}^{2} \mathrm{~s}^{-1}\right]$} & \multirow[t]{2}{*}{$\mathrm{R}^{2}$} & \multicolumn{2}{|c|}{ Coeficientes de Page } \\
\hline & $\mathrm{T}_{\mathrm{sec}}\left({ }^{\circ} \mathrm{C}\right)$ & $\mathrm{v}(\mathrm{m} / \mathrm{s})$ & & & $\mathrm{G}$ & $\mathrm{j}$ \\
\hline 1 & 60,0 & 0,50 & 4,75 & 0,997 & 0,033 & 0,883 \\
\hline 2 & 80,0 & 0,50 & 8,17 & 0,998 & 0,036 & 0,978 \\
\hline 3 & 60,0 & 1,00 & 5,58 & 0,997 & 0,037 & 0,884 \\
\hline 4 & 80,0 & 1,00 & 7,91 & 0,998 & 0,056 & 0,856 \\
\hline 5 & 70,0 & 0,75 & 7,28 & 0,998 & 0,047 & 0,885 \\
\hline 6 & 70,0 & 0,75 & 7,68 & 0,998 & 0,043 & 0,915 \\
\hline 7 & 70,0 & 0,75 & 6,21 & 0,997 & 0,029 & 0,971 \\
\hline 8 & 42,5 & 0,75 & 3,51 & 0,997 & 0,029 & 0,853 \\
\hline 9 & 112,8 & 0,75 & 10,36 & 0,989 & 0,050 & 1,044 \\
\hline 10 & 70,0 & 0,35 & 5,80 & 0,997 & 0,041 & 0,868 \\
\hline 11 & 70,0 & 1,41 & 7,12 & 0,996 & 0,026 & 1,029 \\
\hline
\end{tabular}

A equação empírica de Page apresentou excelente ajuste com valores do coeficiente de determinação acima de 0,99 .

Conforme se pode observar, apesar de os dois modelos apresentarem a mesma tendência nos resíduos, o modelo de Page apresentou melhor ajuste em relação ao modelo de Fick, revelado pelos altos coeficientes de correlação.

Notou-se que, quanto maior a variável codificada de temperatura, maior é a difusividade efetiva. Os parâmetros estimados a partir do programa STATISTICA indicaram que, nessa faixa de valores, somente a variável independente temperatura do ar foi significativa, ajustando a curva para um modelo de primeira ordem. Isso significa que somente a temperatura do ar mantém influência significativa sobre a difusividade efetiva. A influência da temperatura do ar de secagem também foi encontrada por FIGUEIRA et al. (2004), trabalhando com secagem de raízes de chicória. Já em relação à variável codificada de velocidade do ar, isso também é observado, porém com influência menor. $\mathrm{O}$ modelo matemático codificado obtido é mostrado na eq.(7):

$$
\mathrm{D}_{\text {ef }}=6,79710^{-10}+1,43810^{-10} \mathrm{~T}
$$

Pela Figura 4, observa-se que, para as condições do ensaio 9, seria mais indicado diminuir o período entre pesagens no início do processo de secagem, para que o ajuste da curva de secagem fosse mais suave, contendo menores erros experimentais. 


\section{CONCLUSÕES}

Os modelos de Fick e de Page se ajustaram bem aos dados experimentais. Para os valores de difusividade efetiva calculada, somente a temperatura do ar mostrou-se significativa, sendo que a velocidade do ar não se apresentou significativa para a região de valores analisada. O modelo preditivo de difusividade efetiva obtido foi um modelo de primeira ordem. Os valores da difusividade efetiva obtidos variaram entre $3,51 \times 10^{-10}$ e $10,36 \times 10^{-10} \mathrm{~m}^{2} \mathrm{~s}^{-1}$.

\section{AGRADECIMENTOS}

À Fundação de Amparo à Pesquisa do Estado de São Paulo - FAPESP, ao Conselho Nacional de Desenvolvimento Científico e Tecnológico - CNPq, à Coordenação de Aperfeiçoamento de Pessoal de Nível Superior - CAPES, e à Universidade Estadual de Campinas - UNICAMP, que fomentaram este trabalho.

\section{REFERÊNCIAS}

ASSOCIATION OF OFFICIAL ANALYTICAL CHEMISTS. Official methods of analysis of A.O.A.C. International. $16^{\text {th }}$ ed. Arlington: A.O.A.C., 1995. $949 \mathrm{p}$

BRACKEL, J. Van. Mass transfer in convective drying In: MUJUMDAR A.S. Advances in drying. Washington: Hemisphere Publishing Corporation, 1980. p.217-67.

BROD, F.P.R.; ALONSO, L.F.T.; PARK, K.J. Secagem de produtos agrícolas. In: SEMEAGRI SEMANA DE ENGENHARIA AGRÍCOLA DA UNICAMP, 11., 1999, Campinas. Apostila... Campinas: Agrológica, 1999. 122 p.

BROD, F.P.R.; PARK, K.J.; OLIVEIRA, R.A. Modelos matemáticos para representar a secagem de raiz de chicória. Engenharia Agrícola, Jaboticabal, v.23, n.2, p.354-63, 2003.

CRANK, J. The mathematics of diffusion. $2^{\text {nd }}$ ed. Oxford: Clarendon Press, 1975. 414 p.

DAUDIN, J.D. Calcul des cinétiques de séchage par l'air chaud des produits biologiques solides. Sciences des Aliments, Paris, v.3, n.1, p.1-36, 1983.

FIGUEIRA, G.M.; PARK, K.J.; BROD, F.P.R.; HONÓRIO, S.L. Evaluation of desorption isotherms, drying rates and inulin concentration of chicory roots (Cichorium intybus L.) with and without enzymatic inactivation. Journal of Food Engineering, Oxford, v.63, n.3, p.273-80, 2004.

FORNELL, A.; BIMBENET, J.J.; ALMIN, Y. Experimental study and modelization for air drying of vegetable products. Lebensmittel-Wisenschaft \& Technologie, London v.14, n.1, p.96-100, 1980.

PAGE, G.E. Factors influencing the maximum of air drying shelled corn in thin layer. 1949. Thesis (M.Sc.) - Purdue University, Indiana, 1949.

SARAVACOS, G.D.; CHARM, S.E. A study of the mechanism of fruit and vegetable dehydration. Food Technology, Chicago, n.16, n.1, p.78-81, 1962.

SHERWOOD, T.K. The drying of solids (I). Industrial and Engineering Chemistry, Washington, v.21, n.1, p.12-16, 1929a.

SHERWOOD, T.K. The drying of solids (II). Industrial and Engineering Chemistry, Washington, v.21, n.10, p.976-80, 1929b.

STATISTICA for Windows 5.0. Computer program manual. Tulsa: StatSoft, 1995. 